\title{
QUANTITATIVE LIGNIN ANALYSIS BASED ON PERMANGANATE OXIDATION
}

\author{
Jim Parkås, ${ }^{\text {a†* }}$ Gösta Brunow, ${ }^{\mathrm{b}}$ and Knut Lundquist ${ }^{\mathrm{a}}$ \\ Qualitative lignin analysis relies rather much on studies of lignin \\ degradation products. As concerns precise quantification of lignin's \\ composition such studies in general have obvious limitations. Aromatic \\ acids obtained on permanganate oxidation of pretreated lignins \\ (cleavage of ethers and alkylation of phenolic groups) offer a possibility \\ to estimate the amounts of differently substituted aromatic units in \\ lignins. An equation is derived for the calculation of the gross \\ composition of lignins based on the yields of methoxy-substituted \\ aromatic acids obtained on permanganate oxidation of lignins with \\ methylated phenolic groups. The equation could also be used for the \\ calculation of the phenolic content in a lignin sample based on \\ permanganate oxidation data, provided that such data are available for a \\ similar lignin sample with known phenolic content. Literature data for \\ milled wood lignin from spruce are used to exemplify the calculations.
}

Keywords: Aromatic acids, Calculation, Lignin, Oxidation, Permanganate, Phenol

Contact information: a: Forest Products and Chemical Engineering, Department of Chemical and Biological Engineering, Chalmers University of Technology, SE-41296 Göteborg, Sweden; b: Department of Chemistry, PO Box 55, FIN-00014, University of Helsinki, Finland; $†$ : Present address: Södra Cell AB, R\&D, SE-43024Väröbacka, Sweden; *Corresponding author: jim.parkas@sodra.com

\section{INTRODUCTION}

Degradation methods such as acidolysis (Lundquist 1992) and thioacidolysis (Rolando et al. 1992; Önnerud et al. 2003) provide lignin degradation products that in general can be traced to particular lignin structures with confidence. However, the analyses comprise primarily monomeric degradation products, and the examinations of dimeric degradation products are incomplete. Quantitative studies using these techniques are therefore essentially restricted to "uncondensed" units ("uncondensed" and "condensed" units are defined in Fig. 1). One group of lignin degradation methods [thioacetolysis (Nimz 1974), thioacidolysis/Raney Ni treatment (Lapierre et al. 1991), DFRC (Lu and Ralph 1998; Peng et al. 1998)] involves a degradation step and a subsequent reduction step. In these cases both monomeric and dimeric products are thoroughly investigated. Even so, the results represent "uncondensed" units to a greater extent than "condensed" units. The limitations of the degradation/reduction methods also pertain generally for hydrogenolysis (Sakakibara 1992). Degradation methods that permit the analysis of both "condensed" and "uncondensed" lignin units are permanganate oxidation (Erickson et al. 1973b; Gellerstedt 1992), nitrobenzene oxidation (Chen 1991), and the nucleus exchange method (Funaoka et al. 1992). Ozonation (Akiyama et al. 2005 
and preceding work) offers a possibility to quantitatively analyze different types of side chains in lignins.<smiles>[R]c1cc(CCC)cc([R])c1OC</smiles>

$$
\begin{aligned}
& \text { H } \mathrm{R}=\mathrm{R}^{\prime}=\mathrm{H} \\
& \text { G } \mathrm{R}=\mathrm{H}, \mathrm{R}^{\prime}=\mathrm{OCH}_{3} \\
& \text { S } \mathrm{R}=\mathrm{R}^{\prime}=\mathrm{OCH}_{3}
\end{aligned}
$$

Fig.1. H, G and S represent different types of "uncondensed" lignin units. H, G and S units bound to another phenylpropane unit in additional ring positions $(2,3,5$ or 6$)$ are designated "condensed" units.

Much attention has been paid to calculations of the composition of lignins based on results from permanganate oxidation studies (Erickson et al. 1973b; Morohoshi and Glasser 1979; Chen 1991; Gellerstedt 1992; Bose et al. 1998). A schematic description of the reaction sequence involved in these studies is shown in Fig. 2; the aromatic acids are usually analyzed as methyl esters.<smiles>CCC(C)c1ccc(OC)c(OC)c1</smiles>

\section{Lignin unit}

Fig.2. Schematic description of the reactions involved in methylation/permanganate oxidation/esterification of lignin leading to esters of methoxylated aromatic acids. 
Analysis of lignins by permanganate oxidation is advantageous, since the degradation reaction has been thoroughly studied (Erickson 1973a), and convenient methods for the analysis of the degradation products have been worked out (Erickson 1973a). Furthermore, this degradation method specifically concerns phenolic lignin units (Fig. 2). In this paper we introduce an alternative method for the calculation of the compositions of lignins based on degradation products from permanganate oxidation studies. In conformity with all the earlier published calculation methods we have assumed that all the individual types of carbon atoms, attached to aromatic nuclei and susceptible to permanganate oxidation, are converted to carboxyl groups to the same extent. For the sake of simplicity we have restricted the presentation here to spruce lignin. We think that the principles for the calculations presented may be applicable to other degradation methods than permanganate oxidation.

\section{MATERIALS AND METHODS}

\section{Conditions Used in the Cited Experimental Work}

Results from permanganate oxidation studies of spruce lignin (milled wood lignin, MWL) published by Miksche and co-workers (Erickson et al. 1973b) are used as an example in the calculations presented in this paper. Erickson et al. (1973a,b) methylated the phenolic groups in MWL (dimethyl sulfate/KOH). The methylated lignin was degraded to aromatic acids by oxidation with $\mathrm{KMnO}_{4} / \mathrm{NaIO}_{4}$ complemented with a $\mathrm{H}_{2} \mathrm{O}_{2}$ treatment in a subsequent reaction step. The obtained aromatic acids were esterified with diazomethane and analysed by gas chromatography.

\section{Deduction of Equations}

The calculations are based on the yield (mg/100 $\mathrm{mg}$ lignin) of permanganate oxidation/esterification products I-VII (Fig. 3) and the amount of "trace constituents".<smiles>COC(=O)c1ccc(OC)cc1</smiles>

I MW: 166.18<smiles>COc1ccc(C(C)=O)cc1OC</smiles>

II MW:196.20<smiles>COC(=O)c1cc(OC)c(OC)c(OC)c1</smiles>

III MW:226.23
IV

MW:254.24<smiles>COC(=O)c1cc(OC)c(OC)cc1Cl</smiles>
V MW:254.24<smiles>COc1cc(C)ccc1Oc1cc(C(C)=O)cc(OC)c1OC</smiles>

VI MW: 376.37<smiles>COC(=O)c1cc(OC)c(OC)c(-c2cc(C(C)=O)cc(OC)c2OC)c1</smiles>

VII MW: 390.39

Fig.3. Esters obtained on methylation/permanganate oxidation/esterification of spruce lignin. 
Esters of "trace constituents" constituted 3-5\% of the total of the esters (Erickson et al. 1973b). As an approximation we have assumed that 3-5\% of the spruce lignin sample consists of "trace constituents." Judged by the composition of the "trace constituents" (Larsson and Miksche 1969) we assume in the calculations that they consist of equal amounts of $\mathrm{H}$ and $\mathrm{G}$ units. The calculations are based on assumed or determined contents of phenolic groups (phenolic groups/phenylpropane unit). It is only aromatic acids from phenolic lignin units with protected phenolic group (alkylation, often methylation) that are analyzed in permanganate oxidation studies (Fig. 2). An equation (Equation A) has been derived for the calculations. It is assumed that all the individual types of carbon atoms, attached to aromatic nuclei and susceptible to permanganate oxidation, are converted to carboxyl groups to the same extent. The fraction of these carbon atoms that is converted to carboxylic groups is designated F. The conversion factor F can be calculated using Equation A. This equation is based on the condition that the amount (weight) of phenolic units in the lignin sample investigated must be equal to the amount of units (weight) derived from esters I-VII using the conversion factor F together with the phenolic fraction of the "trace constituents" (assumed to be phenolic to the same extent as the rest of the lignin). Note that the extent of conversion to dicarboxylic acids is determined by $\mathrm{F}^{2}$. The determined factor $\mathrm{F}$ is used to calculate the distribution of different types of units in the lignin sample investigated. Furthermore it is possible to calculate the phenolic content in a lignin sample from Equation A provided the factor $\mathrm{F}$ is known. Equation A:

$$
\begin{aligned}
& \frac{\mathrm{I}(\mathrm{mg}) \times 157}{166.2 \times \mathrm{F}}+\frac{\mathrm{II}(\mathrm{mg}) \times 187}{196.2 \times \mathrm{F}}+\frac{\mathrm{III}(\mathrm{mg}) \times 217}{226.2 \times \mathrm{F}}+\frac{\mathrm{IV}(\mathrm{mg}) \times 187}{254.2 \times \mathrm{F}^{2}}+\frac{\mathrm{V}(\mathrm{mg}) \times 187}{254.2 \times \mathrm{F}^{2}}+\frac{2 \times \mathrm{VI}(\mathrm{mg}) \times 187}{376.4 \times 2 \times \mathrm{F}^{2}}+ \\
& \left.\left.\frac{2 \times \mathrm{VII}(\mathrm{mg}) \times 187}{390.4 \times \mathrm{F}^{2}}+\mathrm{Ph} \times \text { Trace (total amount in the sample, } \mathrm{mg}\right)=\mathrm{Ph} \times[100 \text { (lignin sample, } \mathrm{mg})-\text { Carbohydrates }(\mathrm{mg})\right]
\end{aligned}
$$

[The degradation of a $100 \mathrm{mg}$ sample of the lignin is considered, $\mathrm{Ph}$ is the fraction of the lignin units that is phenolic, designations and molecular weights of the degradation products (esters I-VII) appear in Fig. 3, the average lignin unit weights 157, 187 and 217 (corresponding to H, G and S units, Fig. 1) are taken from Larsson and Miksche (1971)].

When the factor $\mathrm{F}$ is known, it is possible to calculate the distribution of lignin units corresponding to esters I-VII and "trace constituents". For example, the fraction (\%) of "uncondensed" G units (represented by ester II) is obtained by dividing the calculated amount (mmol) of such units:

$$
\frac{\mathrm{II}(\mathrm{mg}) \times 100}{196.2 \times \mathrm{F}}
$$

with the total amount (mmol) of calculated lignin units [trace constituents assumed to consist of equal amounts of $\mathrm{H}$ and $\mathrm{G}$ units (Larsson and Miksche 1969)]:

$$
\frac{\mathrm{I}(\mathrm{mg})}{166.2 \times \mathrm{F}}+\frac{\mathrm{II}(\mathrm{mg})}{196.2 \times \mathrm{F}}+\frac{\mathrm{III}(\mathrm{mg})}{226.2 \times \mathrm{F}}+\frac{\mathrm{IV}(\mathrm{mg})}{254.2 \times \mathrm{F}^{2}}+\frac{\mathrm{V}(\mathrm{mg})}{254.2 \times \mathrm{F}^{2}}+\frac{2 \times \mathrm{VI}(\mathrm{mg})}{376.4 \times \mathrm{F}^{2}}+\frac{2 \times \mathrm{VII}(\mathrm{mg})}{390.4 \times \mathrm{F}^{2}}+
$$

$\mathrm{Ph} \times$ Trace (total amount in the sample, $\mathrm{mg}$ )

$$
(157+187) / 2
$$


A second equation (Equation B) for the determination of the conversion factor $\mathrm{F}$ and the calculation of the distribution of units has been presented (Parkås et al. 2004). This equation is based on the same premises as Equation A, excepting that it is assumed that a pretreatment has resulted in a complete cleavage of phenolic ethers connecting lignin units (excepting the very stable diaryl ethers). Equation B (the designations are the same as those in Equation A):

$$
\begin{aligned}
& \frac{\mathrm{I}(\mathrm{mg}) \times 157}{166.2 \times \mathrm{F}}+\frac{\mathrm{II}(\mathrm{mg}) \times 187}{196.2 \times \mathrm{F}}+\frac{\mathrm{III}(\mathrm{mg}) \times 217}{226.2 \times \mathrm{F}}+\frac{\mathrm{IV}(\mathrm{mg}) \times 187}{254.2 \times \mathrm{F}^{2}}+\frac{\mathrm{V}(\mathrm{mg}) \times 187}{254.2 \times \mathrm{F}^{2}}+\frac{2 \times \mathrm{VI}(\mathrm{mg}) \times 187}{376.4 \times \mathrm{F}^{2}}+ \\
& \left.\left.\frac{2 \times \mathrm{VII}(\mathrm{mg}) \times 187}{390.4 \times \mathrm{F}^{2}}+\text { Trace (total amount in the sample, } \mathrm{mg}\right)=100 \text { (lignin sample, } \mathrm{mg}\right)- \text { Carbohydrates }(\mathrm{mg})
\end{aligned}
$$

\section{Excel Files for the Calculations}

Excel files for the calculations are available on the website: http://www.sikt.chalmers.se/lignin/

Further details regarding the calculations are also given at this web-site. The Excel files can alternatively be obtained from the authors on request. The files are designed to solve a second order equation (Equation A or Equation B), which gives the conversion factor F. Based on this, the distribution of lignin units is calculated simultaneously. Calculations based on Equation A (Method Phenolic) and Equation B (Method Quadratic) are exemplified in the Excel-files. Calculations based on Equation B are also discussed by Parkås et al. (2004). The Excel-files can readily be adapted to calculations involving derivatives of the degradation acids other than I-VII (e.g. ethyl esters instead of methyl esters). Similarly unit weights can be adjusted to the type of lignin analyzed.

\section{RESULTS AND DISCUSSION}

\section{General}

Aromatic carboxylic acids obtained on permanganate oxidation of methylated lignins were subjected to detailed studies by Freudenberg and co-workers (Freudenberg 1968), and this approach to lignin analysis has later been extensively employed by several groups (Erickson et al. 1973b; Morohoshi and Glasser 1979; Chen 1991; Gellerstedt 1992; Bose et al. 1998; Tamminen and Hortling 1999). Figure 2 shows the reaction sequence involved in these studies; the aromatic acids are usually analyzed as methyl esters, but in some studies the initial methylation of phenolic groups has been replaced by an ethylation. A method for the analysis of the non-esterified acids has also been described (Javor et al. 2003). Important improvements of the lignin analysis based on permanganate oxidation were introduced by Miksche and co-workers (Erickson et al. 1973a). Experiments with lignin model compounds have shown that diarylmethane structures give only low yields of aromatic acids on permanganate oxidation (Erickson et al. 1973a; Meguro et al. 1998). However, such structures are not present in significant amounts in MWL of spruce (Erickson et al. 1973b). Another complication is that pretreatment with $\mathrm{CuO} / \mathrm{NaOH}$ (to cleave ethers) results in formation of small amounts of 
biphenyls (Bose et al. 1998). It is important to be aware of that it is only the phenolic portion of the lignin samples that is analyzed.

\section{Determination of the Gross Composition of Lignins}

Calculation of the structure of MWLs based on results from permanganate oxidation was introduced by Miksche and co-workers (Larsson and Miksche 1971; Erickson et al. 1973b). The calculations are based on the assumption that all the individual types of carbon atoms susceptible to permanganate oxidation and attached to aromatic nuclei are converted to carboxyl groups to the same extent. A further assumption is that a pretreatment with $\mathrm{CuO} / \mathrm{NaOH}$ results in a complete cleavage of ethers connecting the lignin units (excepting the very stable diaryl ethers). An equation for this type of calculations was derived by Parkås et al. (2004) (Equation B, see Materials and Methods). A factor (F) for the conversion of carbon substituents to carboxyl groups can be calculated using this equation. Other groups (Gellerstedt 1992; Chen 1991) employ a value of conversion factor $F$ based on permanganate oxidation experiments with lignin model compounds. A drawback, in this case, is that there is no connection between the magnitude of the factor and the actual yields of aromatic acids obtained from the particular lignin sample investigated. It has been recognized by two groups (Morohoshi and Glasser 1979; Bose et al. 1998) that a $\mathrm{CuO} / \mathrm{NaOH}$ pretreatment to cleave ethers does not result in a complete cleavage of ether bonds and that some decomposition of lignin units may occur during this treatment. They have modified the conversion factor $\mathrm{F}$ in different ways to compensate for this. It is a fact (cf. Bose et al. 1998) that it is solely the phenolic portion of a lignin sample that give rise to esters I-VII (Figs. 2 and 3). We have derived an equation (Equation A, see Materials and Methods) in which this fact is taken into account, i.e. it is only the phenolic fraction of the samples that is considered in the calculations.

Erickson et al. (1973b) have published yields of I-VII (Fig. 3) obtained on permanganate oxidation of $\mathrm{CuO} / \mathrm{NaOH}$ pretreated spruce MWL. Using their data we have applied Equation A to calculations of the distribution of units in spruce MWL. Table 1 shows the calculated distribution of units in spruce lignin assuming different phenolic contents. Undoubtedly the phenolic content of $\mathrm{CuO} / \mathrm{NaOH}$ treated spruce $\mathrm{MWL}$ is high, but to our knowledge, it has not been determined experimentally. However, Bose et al. (1998) have determined the phenolic fraction of the lignin in $\mathrm{CuO} / \mathrm{NaOH}$ treated spruce wood as $69 \%$. One of the columns in the table shows a distribution of units practically identical with that obtained when the equation presented by Parkås et al. (2004) (Equation B) is applied. It is obvious from calculations based on Equation A (Table 1) that, provided the yields of esters are unchanged, a lower phenolic content (determined or assumed) requires a larger conversion factor $(\mathrm{F})$, which in turn implies larger amounts of "uncondensed" units. The composition of the non-phenolic fraction is not known. It follows that the calculated distribution of lignin units is reliable only if the phenolic content is high and specified in the calculations. In that case the influence of the composition of the non-phenolic fraction on the gross composition of the lignin can be neglected.

The percentages of different types of units corresponding to esters I-VII given by Erickson et al. (1973b) are based on considerations similar to those expressed in 
mathematical form in Equation B (cf. Parkås et al. 2004). However, their choice of conversion factor F is not based on precise calculations (cf. Larsson and Miksche 1971). Their results fairly closely correspond to those calculated based on Equation A, assuming a phenolic content of approx. $85 \%$. Since this is not very far from a probable phenolic content, the structural conclusions drawn by Erickson et al. (1973b) agrees fairly well with those derived from calculations based on Equation A. However, Equation A suggests a slightly lower proportion of "condensed" units.

Table 1. Distribution (\%) of the lignin units in a spruce MWL sample (assumed carbohydrate content 1\%) that gives rise to esters I-VII (Fig. 3). The distribution is calculated (Equation A) based on the yields of these esters (Erickson et al. $1973 b)$ obtained on esterification of aromatic acids formed on permanganate oxidation of the $\mathrm{CuO} / \mathrm{NaOH}$ treated and methylated sample assuming $70 \%, 80 \%$, $90 \%$ or $96.5 \%$ phenolic units after the $\mathrm{CuO} / \mathrm{NaOH}$ treatment. Regarding the interpretation of permanganate oxidation results in terms of structural elements in lignin, see Erickson et al. (1973 b).

\begin{tabular}{lccccc}
\hline & $\begin{array}{c}\text { Amount } \\
\text { (mg/100 mg lignin) }\end{array}$ & $\begin{array}{c}\text { Distribution } \\
\text { assuming 70\% } \\
\text { phenolic units } \\
\text { (gives F=0.69) }\end{array}$ & $\begin{array}{c}\text { Distribution } \\
\text { assuming 80\% } \\
\text { phenolic units } \\
\text { (gives F=0.63) }\end{array}$ & $\begin{array}{c}\text { Distribution } \\
\text { assuming 90\% } \\
\text { phenolic units } \\
\text { (gives F=0.57) }\end{array}$ & $\begin{array}{c}\text { Distribution } \\
\text { assuming 96.5\% } \\
\text { phenolic units } \\
\text { (g** }\end{array}$ \\
\hline I & 0.7 & 1.59 & 1.53 & 1.48 & 1.45 \\
II & 29.8 & 57.31 & 55.18 & 53.30 & 52.19 \\
III & 0.5 & 0.83 & 0.80 & 0.78 & 0.76 \\
IV* & 5 & 10.75 & 11.42 & 12.00 & 12.35 \\
V & 1.1 & 2.37 & 2.51 & 2.64 & 2.72 \\
VI & 2.1 & 6.10 & 6.48 & 6.81 & 7.01 \\
VII & 6 & 16.81 & 17.84 & 18.76 & 19.31 \\
Trace & 4 & 4.24 & 4.23 & 4.22 & 4.22 \\
\hline
\end{tabular}

* Assumed to originate from $\beta-5$ linked units (a contribution from 5-5 linked units is unlikely here since $\mathrm{CuO} / \mathrm{NaOH}$ treatment results in extensive ether cleavage).

** Trace constituents, assumed to consist of equal amounts of $\mathbf{H}$ and $\mathbf{G}$ units (Larsson and Miksche 1969).

*** Comparable with calculations based on Equation B

\section{Determination of Phenolic Groups in a Lignin Sample based on the Yields of I-VII on Permanganate Oxidation}

It is possible to calculate the phenolic content in a lignin sample from the yields of I-VII using Equation A, provided that the conversion factor F is known. A probable factor F can be calculated using Equation A if data (phenolic content, yields of I-VII) 
for a related lignin sample are known. Insertion of the yields of I-VII from spruce MWL reported by Erickson et al. (1973b) and the phenolic content (0.26) in spruce MWL adopted by these authors in Equation $\mathbf{A}$ gives the conversion factor (F) 0.70. Insertion of this factor and the yields of I-VII from $\mathrm{CuO} / \mathrm{NaOH}$ treated MWL [reported by Erickson et al. (1973b) and shown in Table 1] in Equation A gives the phenolic content 0.69. Interestingly, this phenolic content in $\mathrm{CuO} / \mathrm{NaOH}$ treated spruce $\mathrm{MWL}$ agrees with the value (also 0.69) reported by Bose et al. (1998) for the lignin in $\mathrm{CuO} / \mathrm{NaOH}$ treated spruce wood. However, it should be kept in mind in this context that untreated spruce MWL is not an ideal reference lignin for $\mathrm{CuO} / \mathrm{NaOH}$ treated lignin. Gellerstedt (1992) has estimated the phenolic content in lignins based on permanganate oxidation. In this case a conversion factor for formation of aromatic acids was selected based on model compound studies.

\section{CONCLUSIONS}

1. The calculation method developed (exemplified using the cited experimental work) improves the comparability of results obtained with different samples, since it is based on the fact that the phenolic content of the lignin sample examined defines the theoretical yield of the methoxylated acids obtained on methylation/permanganate oxidation.

2. The equations derived for the calculations make it possible to treat input data in a consistent way. "Trace constituents" and carbohydrate content are considered in the equations.

3. The solution of the equations using Excel-files is convenient. The Excel-files are readily adapted to different types of derivatives of the degradation acids. Similarly the parameters used in this paper can readily be replaced by others.

\section{REFERENCES CITED}

Akiyama, T., Goto H., Nawawi D.S., Syafii W., Matsumoto, Y., and Meshitsuka, G. (2005). "Erythro/threo ratio of beta-O-4-structures as an important structural characteristic of lignin. Part 4: Variation in the erythro/threo ratio in softwood and hardwood lignins and its relation to syringyl/guaiacyl ratio," Holzforschung 59(3), 276-281.

Bose, S. K., Wilson, K. L., Francis, R. C., and Aoyama, M. (1998). "Lignin analysis by permanganate oxidation. I. Native spruce lignin," Holzforschung 52(3), 297-303.

Chen, C.-L. (1991). "Lignins: Occurrence in woody tissues, isolation, reactions, and structure," In: Wood Structure and Composition, M. Lewin, and I. S. Goldstein (eds.), Marcel Dekker, New York, 184-261.

Erickson, M., Larsson, S., and Miksche, G. E. (1973a). "Gaschromatographische Analyse von Ligninoxydationsprodukten. VII. Ein verbessertes Verfahren zur Charakterisierung von Ligninen durch Methylierung und oxydativen Abbau," Acta Chem. Scand. 27(1), 127-140. 
Erickson, M., Larsson, S., and Miksche, G.E. (1973b). “Gaschromatographische Analyse von Ligninoxydationsprodukten. VIII. Zur Struktur des Lignins der Fichte, “ Acta Chem. Scand. 27(3), 903-914.

Freudenberg, K. (1968). "The constitution and biosynthesis of lignin" In: Constitution and Biosynthesis of Lignin. K. Freudenberg, and A. C. Neish (eds.), Springer-Verlag, Berlin-Heidelberg, 47-122.

Funaoka, M., Abe, I., and Chiang, V. L. (1992). "Nucleus exchange reaction" In: Methods in Lignin Chemistry, S. Y. Lin, and C. W. Dence (eds.), Springer-Verlag, Berlin, 369-386.

Gellerstedt, G. (1992). "Permanganate oxidation” In: Methods in Lignin Chemistry, S. Y. Lin, and C. W. Dence (eds.), Springer-Verlag, Berlin, 322-333.

Javor, T., Buchberger, W., and Faix, O. (2003). "Capillary electrophoretic determination of lignin degradation products obtained by permanganate oxidation," Anal. Chim. Acta 484(2), 181-187.

Lapierre, C., Pollet, B., Monties, B., and Rolando, C. (1991). "Thioacidolysis of spruce lignin: GC-MS analysis of the main dimers recovered after Raney nickel desulphuration," Holzforschung 45(1), 61-68.

Larsson, S., and Miksche, G.E. (1969). "Gaschromatographische Analyse von Ligninoxydationsprodukten. III. Oxydativer Abbau von methyliertem BjörkmanLignin (Fichte)," Acta Chem. Scand. 23(10), 3327-3351.

Larsson, S., and Miksche, G.E. (1971). "Gaschromatographische Analyse von Ligninoxydationsprodukten. IV. Zur Struktur des Lignins der Birke," Acta Chem. Scand. 25(2), 647-662.

Lu, F., and Ralph, J. (1998). "The DFRC method for lignin analysis. 2. Monomers from isolated lignins," J. Agric. Food Chem. 46(2), 547-552.

Lundquist, K. (1992). “Acidolysis” In: Methods in Lignin Chemistry, S. Y. Lin, and C. W. Dence (eds.), Springer-Verlag, Berlin, 289-300.

Meguro, S., Xu, H., and Lai, Y.-Z. (1998). "Reactivity of lignin diphenylmethane model dimers. 2. Permanganate oxidation," Holzforschung 52(2), 175-179.

Morohoshi, N., and Glasser, W.G. (1979). "The structure of lignins in pulps. Part 5: Gas chromatography of permanganate oxidation products," Wood Sci. Technol. 13(4), 249-264.

Nimz, H. (1974). "Beech lignin - proposal of a constitutional scheme," Angew. Chem. Internat. Edit. 13(5), 313-321.

Parkås, J., Lundquist, K., and Brunow, G. (2004). "Quantitative lignin analysis, “ Proc. 8th European Workshop on Lignocellulosics and Pulp, Riga, Latvia, August 22-25. pp. 271-274.

Peng, J., Lu, F., and Ralph J. (1998). "The DRFC method for lignin analysis. 4. Lignin dimers isolated from DFRC-degraded loblolly pine wood," J. Agric. Food Chem. 46(2), 553-560.

Rolando, C., Monties, B., and Lapierre, C. (1992). "Thioacidolysis” In: Methods in Lignin Chemistry, S. Y. Lin and C. W. Dence (eds.), Springer-Verlag, Berlin, 334349.

Sakakibara, A. (1992). "Hydrogenolysis," In: Methods in Lignin Chemistry, S. Y. Lin, and C. W. Dence (eds.), Springer-Verlag, Berlin. pp. 350-368. 
Tamminen, T. L., and Hortling, B. R. (1999). "Isolation and characterization of residual lignin” In: Advances in Lignocellulosics Characterization, D. S. Argyropoulos (ed.), TAPPI Press, Atlanta, 1-41.

Önnerud, H., Palmblad, M., and Gellerstedt, G. (2003). "Investigation of lignin oligomers using electrospray ionisation mass spectrometry," Holzforschung 57(1), 37-43.

Article submitted: Jan. 29, 2007; First review cycle completed: Feb. 21, 2007; Revised version accepted: March 7, 2007; Published March 9, 2007. 